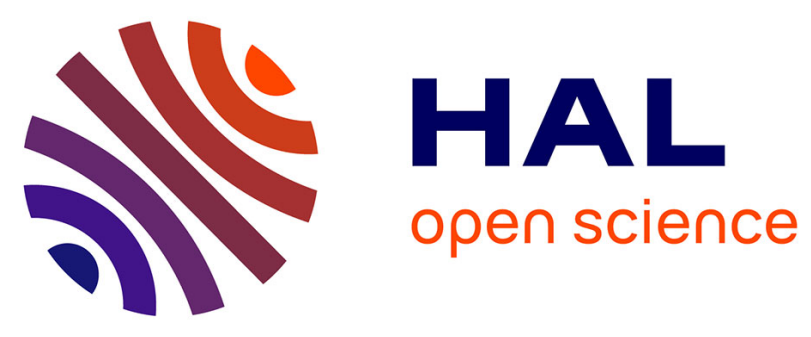

\title{
Beyond species richness and biomass: Impact of selective logging and silvicultural treatments on the functional composition of a neotropical forest
}

Benjamin Yguel, Camille Piponiot, Ariane Mirabel, Aurélie K. Dourdain, Bruno Hérault, Sylvie Gourlet-Fleury, Pierre-Michel Forget, Colin Fontaine

\section{To cite this version:}

Benjamin Yguel, Camille Piponiot, Ariane Mirabel, Aurélie K. Dourdain, Bruno Hérault, et al.. Beyond species richness and biomass: Impact of selective logging and silvicultural treatments on the functional composition of a neotropical forest. Forest Ecology and Management, 2019, 10.1016/j.foreco.2018.11.022 . hal-02750175

\section{HAL Id: hal-02750175 \\ https://hal.science/hal-02750175}

Submitted on 3 Jun 2020

HAL is a multi-disciplinary open access archive for the deposit and dissemination of scientific research documents, whether they are published or not. The documents may come from teaching and research institutions in France or abroad, or from public or private research centers.
L'archive ouverte pluridisciplinaire HAL, est destinée au dépôt et à la diffusion de documents scientifiques de niveau recherche, publiés ou non, émanant des établissements d'enseignement et de recherche français ou étrangers, des laboratoires publics ou privés. 


\title{
Beyond species richness and biomass: Impact of selective logging and silvicultural treatments on the functional composition of a neotropical forest
}

\author{
Benjamin Yguel $^{\mathrm{a}, \mathrm{b}, *}$, Camille Piponiot ${ }^{\mathrm{c}}$, Ariane Mirabel $^{\mathrm{c}}$, Aurelie Dourdain ${ }^{\mathrm{c}}$, Bruno Hérault ${ }^{\mathrm{c}}$, \\ Sylvie Gourlet-Fleury ${ }^{\mathrm{d}}$, Pierre-Michel Forget ${ }^{\mathrm{a}}$, Colin Fontaine ${ }^{\mathrm{b}}$ \\ ${ }^{a}$ Muséum National d'Histoire Naturelle, Département Adaptations du Vivant, UMR 7179 MECADEV CNRS-MNHN, 1 Avenue du Petit Château, 91800 Brunoy, France ${ }^{b}$ \\ Centre d'Ecologie et des Sciences de la Conservation (CESCO), Muséum national d'Histoire naturelle, Centre National de la Recherche Scientifique, Sorbonne Université, \\ CP 135, 57 rue Cuvier, 75005 Paris, France \\ "CIRAD, UMR "Ecologie des Forêts de Guyane" AgroParisTech-CIRAD-INRA-CNRS-Université de Guyane-Université des Antilles, Campus Agronomique, Kourou, Guyane \\ Française, France \\ ${ }^{\mathrm{d}}$ Cirad, UR Forêts et Sociétés, Université de Montpellier, 34398 Montpellier, France
}

\section{A R T I C L E I N F O}

\section{Keywords: Selective}

logging Humid

tropical forest

Functional composition

Seed dispersal Carbon

storage Commercial

stock Anthropogenic

pressure Sustainability

\begin{abstract}
A B S T R A C T
Tropical forests harbor the greatest terrestrial biodiversity and provide various ecosystem services. The increase of human activities on these forests, among which logging, makes the conservation of biodiversity and associated services strongly dependent on the sustainability of these activities. However the indicators commonly used to assess the impact of forest exploitation, namely species richness and biomass, provide a limited understanding of their sustainability.

Here, we assessed the sustainability of common forest exploitation in the Guiana Shield studying the recovery of two ecosystem services i.e. carbon storage and wood stock, and an ecosystem function i.e. seed dispersal by animals. Specifically, we compared total and commercial biomass, as well as functional composition in seed size of animal-dispersed species in replicated forest plots before and 27 years after exploitation. Species richness is also studied to allow comparison.

While species richness was not affected by forest exploitation, total and commercial biomass as well as seed size of animal-dispersed species decreased 27 years after exploitation, similarly to forests affected by hunting. These results show that ecosystem services and function likely did not recover even at the lowest intensity of forest exploitation studied, questioning the sustainability of the most common rotation-cycle duration applied in the tropics.
\end{abstract}

\section{Introduction}

The tropical forest covers about 18 million of $\mathrm{km}^{2}$ (Keenan et al., 2015) and provides a variety of ecosystem services to humans (Edwards et al., 2014). In addition to wood and non-woody forest products, tropical forests harbor the greatest species diversity on earth (Schemske and Mittelbach, 2017) and play a crucial role in the mitigation of climate change by sequestering $30 \%$ of fossil fuel $\mathrm{CO}_{2}$ emissions (Pan et al., 2011), and accounting for at least $59 \%$ of the terrestrial global carbon stocks (Dargie et al., 2017).

However, tropical forests are suffering from heavy anthropogenic pressures (Asner et al., 2009) and their areas are shrinking despite increasing protection and conservation actions (Morales-Hidalgo et al., 2015). More particularly, in 2005 , at least $21 \%$ of the humid tropical forests were already selectively logged, which represented the highest proportion of the FAO's secondary forest category and the most widespread method of logging in the tropics, affecting larger areas than deforestation (Asner et al., 2009). This rise of logged forest makes the conservation of the tropical forest biodiversity and associated services strongly dependent on the sustainability of logging methods (Edwards et al., 2014).

The sustainability of logging methods, a declared goal of international institutions such as FAO, generally refers to methods allowing the exploitation of the resources indefinitely (Dickinson and Putz, 1992, Shearman et al., 2012). Accordingly, a forest should return to the closest pre-logging state in terms of composition but also in terms of biomass before subsequent logging is performed. While an increasing number of studies suggested that current logging practices and harvest

Corresponding author at: Centre d'Ecologie et des Sciences de la Conservation (CESCO), Muséum national d'Histoire naturelle, Centre National de la Recherche Scientifique, Sorbonne Université, CP 135, 57 rue Cuvier, 75005 Paris, France

E-mail address: benyguel@hotmail.fr (B. Yguel). 
rotation cycles in the tropics do not achieve this objective, such assessments are often based on the effects of logging only on species richness, biomass production or carbon storage (Putz et al., 2012, Martin et al., 2015, Piponiot et al., 2016, Rutishauser et al., 2015).

However, species richness and biomass used alone to assess the impact of logging methods give limited information on forest compositional changes, thus on the sustainability of logging methods (Edwards et al., 2014). On the one hand, while carbon storage and biomass production may be good proxies to assess the mitigation of carbon emissions, a same level of these indicators may correspond to different species composition, abundance and diversity (Martin et al., 2013, Ferreiraet al., 2018). We may further notice that these indicators provide no precise information on the number and quality of harvestable trees (Gourlet-Fleury et al., 2013). On the other hand, species richness only gives a partial picture of biodiversity, especially in terms of ecosystem functioning (Leibold et al., 2017, Cernansky, 2017). Indeed, species richness can provide some information according to the relation between biodiversity and ecosystem function (but Chisholm et al., 2013) but provides no information on species identity and associated traits, and therefore on the type of ecosystem functions provided by species, an essential aspect to consider if we want to assess the ability of forest to retrieve its pre-logging state (Hérault \& Piponiot, 2018). Similar species richness may hide changes in species composition and relative abundance as well as in the number of ecosystem functions they fulfill.

Functional composition, defined as the distribution of functional traits within communities, is inherently more informative regarding the function provided, but, in comparison with species richness and biomass, is much rarely used to assess the sustainability of logging activities (Flores et al., 2014, Hogan et al., 2018). Functional composition helps to understand the processes underpinning compositional changes and thus forest dynamics (Edwards et al., 2014). For instance, it is well known that logging alters species composition of forests principally via the openings created by tree removal (Pinard and Cropper, 2000). The openings modify the light environment, and consequently promote species with particular functional traits, i.e. light demanding species (Schnitzer and Carson, 2001) with high growth rate, a character correlated to low wood density (Flores et al., 2014).

Logging may also alter important ecosystem functions such as seed dispersal, by affecting associated functional trait composition, seed size in that case. In particular, logging may affect forest composition by affecting seed dispersal by animals (zoochory) in late successional state of humid neotropical forests, characterized by slow growing, shade tolerant (Molino and Sabatier, 2001) and many animal dispersed species (about $75 \%$ of individuals in our study site Appendix S1). Selective logging directly targets large trees of species with idiosyncratic functional traits combination, including high wood density and large seeds dispersed by animals (Hammond et al., 1996, Forget and Sabatier, 1998). But forest exploitation, that is to say tree removal caused by the logging per se, damages associated to logging, as well as silvicultural treatment further create openings that favor the abundance of light demanding, small seeded and low wood density species (Herault et al., 2010). This may affect resource availability for animal dispersers consuming large seeds, with potential negative cascading effects on the abundance of such dispersers, as well as on the seed dispersal they perform and finally on the abundance of large seeded tree species (Bello et al., 2015, Peres et al., 2016). Because high wood density may be correlated with large seed size, a decrease in seed size can be associated with a decrease in wood density and then in carbon storage (Bello et al., 2015, Peres et al., 2016). Despite being important to evaluate the ability of forests to return to their pre-exploitation state, these aspects are often neglected in the assessment of forest exploitation.

In this study, we assess the sustainability of forest exploitation of various intensity, testing for the recovery of ecosystem services and functions in a neotropical forest after being logged. Specifically, by comparing the composition before and 27 year after exploitation, we quantified changes in species richness, carbon and commercial stock as well as the effects of canopy opening. To do so, we looked at changes in total and commercial biomass, as well as changes in community weighted mean of wood density and light requirement. We further tested the effect of forest exploitation on animal dispersed species analyzing changes in seed size. We performed our analysis using data from a long-term replicated experiment located in French Guiana, where selective logging associated with silvicultural treatments of varying intensity were applied on forest plots never logged before (Gourlet-Fleury et al., 2004). This set up is ideal to evaluate changes in the functional composition of trees as the time since logging treatments is close to the cycle duration commonly used in the tropics (Shearman et al., 2012) and through the use of the common logging method used in the tropics. The gradient of increasing forest exploitation also allows to better highlight functional changes. At last, hunting pressure is considered constant across the study area because of close proximity between plots, difference observed are thus only due to the effect of forest exploitation.

\section{Method}

\subsection{Study site}

Data were collected at the Paracou experimental site $\left(5^{\circ} 18^{\prime} \mathrm{N}\right.$, $52^{\circ} 55^{\prime} \mathrm{W}$ ), a lowland tropical rain forest near Sinnamary, French Guiana. The site receives nearly two-thirds of the annual $3041 \mathrm{~mm}$ of precipitation between mid-March and mid-June, and $<50 \mathrm{~mm}$ per month in September and October (Wagner et al., 2011 Agricultural). The floristic composition is typical of littoral guianan rainforests with dominant families including Leguminoseae, Chrysobalanaceae, Lecythidaceae, Sapotaceae and Burseraceae.

In 1984, 12 plots of 6.25 ha each $(250 \mathrm{~m} \times 250 \mathrm{~m})$ were established at the Paracou site for a complete annual inventory of all trees $\geq 10 \mathrm{~cm}$ DBH (diameter at breast height, at $1.3 \mathrm{~m}$ height). The experimental design was composed of 3 control plots (hereafter T0), 3 plots with selective logging (T1), 3 plots with selective logging and thinning (T2) and 3 plots with selective logging, thinning and fuelwood harvesting (T3). From October 1986 to May 1987, T1, T2 and T3 plots underwent selective logging with an average of 10 trees/ha of commercial species logged with $50 \mathrm{~cm}$ minimum DBH. Silvicultural treatments aiming at thinning and considered as timber stand improvement techniques (TSI) were further applied to $\mathrm{T} 2$ and $\mathrm{T} 3$. This treatment consisted in poisongirdling an average of 30 trees/ha $\geq 40 \mathrm{~cm} \mathrm{DBH} \mathrm{(T2)} \mathrm{and} 20$ trees/ha $\geq 50 \mathrm{~cm} \mathrm{DBH} \mathrm{(T3)} \mathrm{of} \mathrm{non-commercial} \mathrm{species.} \mathrm{At} \mathrm{last,} \mathrm{for} \mathrm{T} 3$, an average of 15 trees/ha $\geq 40 \mathrm{~cm} \mathrm{DBH}$ were cut to mimic fuelwood harvesting. The effects of thinning and fuelwood harvesting are mainly to increase canopy openings, and to further reduce resources for potential disperser thereby. As suggested by the comparison of the surfaces disturbed by forest exploitation (including tree removal, due to the logging per se and due to damage associated to logging as well as silvicultural treatments when applied), the three experimental treatments corresponds to an increase in the intensity of forest openings (Appendix S2). According to Blanc et al. (2009) or Piponiot et al. (2016), treatments applied at Paracou mimic a gradient of disturbance intensities and having higher damage per harvest intensity than other sites conventionally harvested. Each plot was divided into 4 subplots of 1.56 ha for statistical purposes, i.e. 12 subplots for each treatment and the control $(4 \times 3=12)$, and 48 subplots in total.

\subsection{Trees inventory}

In all plots, all trees $\geq 10 \mathrm{~cm}$ DBH have been mapped and measured annually from 1984 to 2013 (Gourlet-Fleury et al., 2004). For this study, we used the census performed in 1984, before logging, and the one performed in 2013 including respectively 46,476 and 50,108 trees. Trees belonging to commercial species were first identified with a 
vernacular name in 1984 followed by trees belonging to non-commercial species in 1992. A total of 253 vernacular names were attributed to trees in 1984 and 2013 at time of data extraction from the Paracou database (December 2017). However, some individuals died before being identified with vernacular names, representing $11 \%$ and $0.3 \%$ of individuals censused in 1984 and 2013, respectively (Appendix S1, Table S1a-S1b).

Since 2003, regular botanical campaigns were performed to get species level identification, allowing to retrospectively obtain species level identifications of trees from the 1984 census that were still alive. A total of 576 species have been recorded in 2017 (i.e. year of data extraction) and species level identifications were missing for $31 \%$ and 19\% of individuals censused in 1984 and 2013, respectively (Appendix S1, Table S1a-S1b).

While we only used the dataset based on species level identification to study species richness and biomass (but Guitet et al., 2014), we used both datasets i.e. based on vernacular identification and on species level identification, to study change in functional trait composition (see functional trait composition below)

\subsection{Species richness}

We assessed species richness of each subplot using data with species level identification and a corrected version of species richness that accounts for differences in sample size and for the non-detection of rare species compensating sampling biases. Calculation was done using the package "entropart" and the function "bcRichness" with the correction "Chao1" (Marcon \& Hérault, 2015).

\subsection{Above ground biomass of commercial and of all species}

We calculated the above ground biomass of all commercial species (total and commercial biomass from hereon) before and 27 years after logging using data with species level identification. Commercial species correspond to all species at Paracou that could be used for any kind of commercial uses. The biomass was calculated for each subplot in 1984 and 2013 with the function computeAGB of the package BIOMASS (Rejou-Mechain et al., 2017) with no consideration for change in height-DBH model due to logging (Rutishauser et al., 2016 Biotropica). This package uses the wood density database of Zanne et al. (2009), described in Chave et al. (2009) and managed by Gaby Lopez-Gonzalez (G.Lopez-Gonzales@leeds.ac.uk). This database gives the wood density at the species level in $\mathrm{g} / \mathrm{cm}^{3}$, and represents the dry mass divided by the fresh volume. Taking into account all individuals for biomass measurement is important because missing individuals can represent an important weight. Thus, for individuals not identified at species level or not identified, the BIOMASS package respectively averaged wood density values per taxonomic level, or assigned the mean wood density per subplot (Appendix S1 for Percentages of individuals with species, genus and mean subplot values). For biomass measurements only, all individuals were taken into account. Because we did not have height measurements, we used the bioclimatic parameter E estimated by Chave et al. (2014) using the coordinates of the Paracou research station and diameter of each tree. Biomass is measured in $\mathrm{Mg}$ (or ton) and by subplots (1.56 ha) and converted in ton per hectares.

\subsection{Functional composition in wood density, seed size and heliophily taking} into account dispersal mode

We studied the functional composition in terms of wood density, seed size (i.e. seed length and width), and heliophily for zoochorous and non-zoochorous species separately. We characterized the functional composition by the community weighted mean (CWM) of each trait per subplot in 1984 and in 2013. The CWM of each trait was calculated using the library "FD" and the function functcomp (Laliberté et al., 2014).
For the analysis of the dataset with species level identification, we assigned to each species a trait value measured directly or found in the literature (see below details on data origin).

For the analysis of the dataset with vernacular identification, as vernacular name are given to species with similar morphological traits, for each trait, the trait values were calculated as the mean trait value of the species that are lumped in the vernacular names.

For seed size, we analyzed seed length and width for tree species that depend on animal for seed dispersal (zoochorous species). The dispersal mode was assessed using in situ observation and literature (Appendix S3). We then used database on seed length and width, including direct measurements from 1998 to 2008 at the study site and data from the literature (Appendix S3). Percentages of individuals with known dispersal mode, percentages of zoochorous species, and percentages of individuals with seed size data are presented in Appendix $\mathrm{S} 1$ (c, d, e).

For wood density, value of each tree species was extracted from the global database (Zanne et al., 2009). Percentages of individuals with wood density are presented in Appendix S1f.

For heliophily, we used a method derived from Molino and Sabatier (2001), based on the percentage of Cecropia obtusa and C. sciadophylla in the 10 closest individuals, measured on the dataset with species level identification in 2013, and averaged per species. Cecropia is one major pioneer tree genus in the neotropics, preferentially developing in noninundated habitats (Berg and Rosselli, 2005). Most of the Cecropia species found in French Guiana were described as forest gap species, very abundant in primary forest clearings (Guitet et al., 2018). The calculation was made on established individual and thus may slightly differ from classification made on germination or growth rate. Percentages of individuals with heliophily are indicated in Appendix S1g.

\subsection{Statistical analyses}

The goal of our study was to compare species richness, biomass and functional composition before and after 27 years after forest exploitation (i.e. 1984 vs 2013). Species richness, total and commercial biomass, as well as functional composition (i.e. CWM) were calculated before and after exploitation at the subplot level. Subplots thus constitute pseudoreplications. As suggested by Millar and Anderson (2004) to deal with pseudoreplication, we only performed non-parametric paired comparison tests to compare species richness, total and commercial biomass as well as CWM values before and after logging treatments. We used the paired Wilcoxon signed rank test using the function wilcox.test, with the option "paired = TRUE" of the R software (2015).

Note that we compared the forest composition before and after the exploitation for each treatment separately instead of comparing the control treatment (T0) with the other treatments due to difference in the initial composition in 1984 between control and harvested plots (Gourlet-Fleury et al., 2004).

The analysis performed on the datasets based on species level and vernacular identifications gave similar results and are presented in the main text and in the appendices respectively (Appendix S6 to S8).

\section{Results}

\subsection{Did exploited subplots recover their initial species richness?}

We found no difference in the corrected species richness before and 27 years after logging for the control treatment (T0), nor for the selective logging only treatment (T1) or the selective logging plus only thinning treatment (T2). For the selective logging plus thinning and fuelwood treatment (T3), we found a significant increase in corrected species richness 27 years after logging (Appendix S4, Fig. 1). 

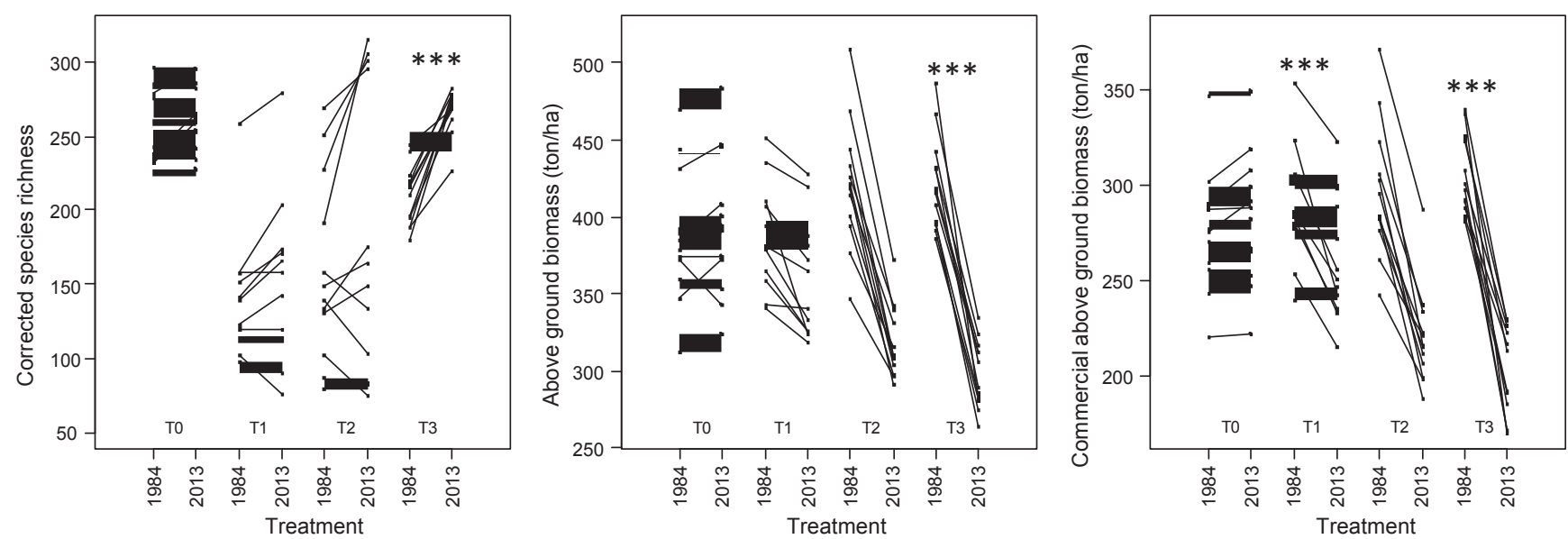

Fig. 1. Changes in corrected species richness, total and commercial biomass 27 years after logging (1984 vs. 2013 ), for each subplot of the treatments. T0 is for control treatment, T1 for selective logging only treatment, T2 for selective logging plus thinning treatment and T3 for selective logging plus thinning and fuelwood treatment. The significance of non-parametric comparison test is indicated by ${ }^{*} \mathrm{p}<0.05,{ }^{* *} \mathrm{p}<0.01,{ }^{* * *} \mathrm{p}<0.001$.

\subsection{Did exploited subplots recover their initial total and commercial biomass?}

Analyzing the total and commercial biomass before and 27 years after logging, we found that total and commercial biomass significantly increased in the control treatment (T0) while it significantly decreases for the three treatments (Appendix S5, Fig. 1). With total and commercial biomass, the decrease of biomass is stronger with increasing logging intensity (Fig. 1).

\subsection{Did exploited subplots recover their initial CWM of wood density} values?

The CWM of wood density decreased significantly 27 years after logging and this decrease was stronger with increasing logging intensity (Appendix S6, Fig. 2). Note that using the dataset with vernacular identification, CWM of wood density did not change significantly with the control treatment T0 (Appendix S6).

\subsection{Did exploited subplots recover their initial CWM seed size of zoochorous species?}

We compared the CWM seed size before and 27 years after logging treatments for zoochorous. We found that the CWM of seed length and of seed width significantly decreased for all treatments, and the decrease was stronger for higher logging intensity (Fig. 2, Appendix S7). Note that using the dataset with vernacular identification, CWM of seed size did not change significantly with the control treatment T0 (Appendix S7).

\subsection{Did exploited subplots recover their initial CWM heliophily values?}

We compared the median heliophily before and 27 years after logging in order to investigate the effect of openings. The CWM values of heliophily did not change significantly in the control while it increased in all other treatments (Appendix S8, Fig. 2). With all datasets the increase of heliophily CWM is stronger with increasing logging intensity.

\section{Discussion}

Our analyses showed that, 27 years after forest exploitation, species richness did not differ from the pre-logging state, except in the treatment with the highest forest exploitation where it tended to increase. In contrast, we found that the total and commercial aboveground biomass as well as the CWM of wood density of all species and seed size of zoochorous species significantly decreased with increasing forest
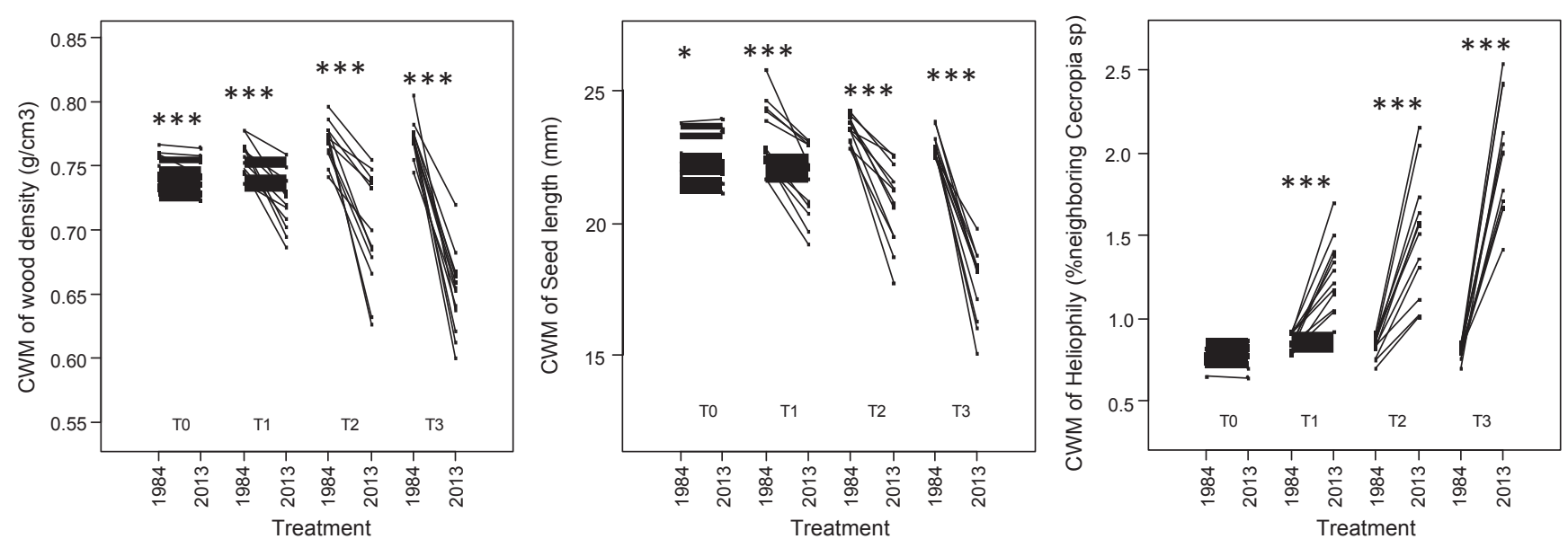

Fig. 2. Changes in CWM of wood density, of seed length and of heliophily 27 years after logging (1984 vs. 2013), for each subplot of the treatments. Analyses were performed for zoochorous species for seed length. T0 is for control treatment, T1 for selective logging only treatment, T2 for selective logging plus thinning treatment and $\mathrm{T} 3$ for selective logging plus thinning and fuelwood treatment. The significance of non-parametric comparison test is indicated by ${ }^{*} \mathrm{p}<0.05,{ }^{* *} \mathrm{p}<0.01$, ${ }^{* * *} \mathrm{p}<0.001$. 
exploitation intensity. This suggests lower provision of ecosystem function such as seed dispersal by animals and ecosystem services such as carbon storage, and timber production. While our results on ecosystem services support previous findings (Flores et al., 2014, Martin et al., 2015), we demonstrate here that logging affect zoochorous species and very likely seed dispersal in similar way than hunting (Bello et al., 2015).

Looking at these results separately can lead to opposite conclusions. Forest exploitation appears not to affect biodiversity conservation when analyzing species richness only, but becomes detrimental if ecosystem function and services are taken into account. Our results fuel the idea that the assessment of the sustainability of forest exploitation cannot be based on species richness alone but requires integrating relevant ecosystem functions and services (Martin et al., 2015).

\subsection{Effect of logging on species richness}

Species richness appeared not affected by the different forest exploitation intensities. This may be explained by the intermediate disturbance hypothesis - i.e. a balance between local immigration and extinction rate (Molino and Sabatier, 2001) - where openings created during forest exploitation favor the establishment of pioneer species that are mostly excluded from old-growth forest. These openings thus select species with high fecundity and/or fast growth, respectively linked to particular traits, i.e. smaller seed size and lower wood density (Dalling and Hubbell, 2002). This is supported by the decrease in CWM in wood density and seed size as well as the increase in CWM of heliophily (Muscarella et al., 2017). Also, selection of only one of this characteristic (high fecundity or fast growth) select for the other as seed size is negatively correlated in general with wood density (Bello et al.,

2015, Appendix S9). As species richness did not change, pioneer species may rather replace than be added to the existing stock of shade tolerant species, a major component of the late successional forests. However, the constancy of the species richness might likely be a transient successional state and might decrease later on (Putz et al., 2012, Edwards et al., 2014).

The increase in species richness observed only in treatment T3 might be due to a difference in proportion of individuals identified (see methods) but could be also due to the increase in forest exploitation intensity and consequently in the number and size of the openings, increasing pioneers species number in addition to the remaining shade tolerant species.

\subsection{Effect of logging on carbon and commercial stock}

Contrasting with the low biomass increase in control plots (Rutishauser et al., 2010), our result showed a decrease in the total and commercial above ground biomass and in the abundance of species with high wood density 27 years after forest exploitation even at the lowest intensity. The intensity of change depended on forest exploitation intensity. As explain above, these changes might be due to openings favoring the arrival of pioneer species with low wood density (Herault et al., 2010). This is also supported by the parallel increase of the intensity of functional composition change and increase of the intensity in opening surfaces created by the three forest exploitation intensities studied (Appendix S2 and Fig. 1). These results support the idea that a rotation cycle of 30 years with the forest exploitation intensities studied are not long enough for humid neotropical forests to recover their initial state, also from the selective logging only treatment. As a consequence, in countries where equal or shorter rotation cycle duration with equal or higher forest exploitation intensity are allowed, we may soon reach a peak in the timber production in the exploited forest (Shearman et al., 2012, Martin et al., 2015, Chaudhary et al., 2016). Note that we studied here a humid tropical forest that may react differently to forest exploitation in comparison with dry tropical forests (Bongers et al., 2009). Indeed, drier forests are characterized by smaller species pool and species with higher heliophily (Bongers et al., 2009) that might be less affected by openings. In these drier forests, wood density might be a better indicator of change than heliophily (Slik et al., 2008), but this remains to be tested. In the same line, our humid neotropical forest harbor high proportion of zoochorous species (Appendix S1) potentially affected by logging (see below) which might not be the case elsewhere.

\subsection{Effect of forest exploitation on seed dispersal}

We observed that the seed size of zoochorous species and thus resources for dispersers and decreased with increasing forest exploitation intensity suggesting that dispersal mediated by animals is likely affected. Also, the abundance of large seeded zoochorous species may have been affected not only by colonization of openings by pioneer species but also by logging or injuring these large seeded species. Two supplementary analyses were done to test specifically the effect of tree killing and removal during forest exploitation per se on animal resources comparing the initial seed size composition with and without the logged, damaged, and poisoned trees (Appendix S10). We then tested the effect of forest exploitation on animal dispersal comparing seed size composition before and 27 years after forest exploitation but in totally undisturbed part of the logged plots (Appendix S11). While seed size of zoochorous species should be affected by forest exploitation with change in the light environment in exploited parts, seed size of zoochorous species should be rather modified by changes in seed dispersal in the unlogged and undisturbed part of the exploited plots. Non zoochorous species should be also not affected, as pioneer should not be favored in these more shadowed forest area.

The first additional analysis showed no change of seed size composition of zoochorous species just after the exploitation, supporting rather the hypothesis of an opening effect (Appendix S10). This results reinforce the idea that openings is the main consequence of forest exploitation, and thus our results should apply to logging of species with any functional traits in the same region and not only to selective logging of zoochorous species with high wood density and seed size.

In addition, we may expect further negative feedback effects of the decrease in CWM of seed size on the dispersal and recruitment of animal-dispersed plants (Hammond et al., 1996, Forget and Sabatier, 1998). Indeed, a decrease in resource for frugivores might decrease animal density according to the resource concentration hypothesis (Root, 1973). Also, one can imagine that openings and surrounding area may be avoided by dispersers to avoid predation. For these reasons, the dispersal mediated by animals could be disrupted for a longer time or irreversibly by such a negative feedback loop. This is supported by the second additional analysis showing that decreases in seed size of zoochorous species are not restricted to logged and disturbed part of the plots where openings were created. The same changes in seed size for zoochorous species are also found in the parts of the experimental plots not directly affected by logging or damage related to it such as tracks for forest machines while non zoochorous are not affected (Appendix S11). However, experimental test and observational data would be needed to ascertain such effects on dispersers. Overall, this supports the assumption that the effect of logging on forest is not restricted to forest area directly affected by logging potentially impacting other processes than light availability, even at the lowest logging intensity and could last longer than the common cutting cycle.

\subsection{Recommendation}

Based on our results, different recommendations can be made in order to improve the sustainability of forest exploitation in humid neotropical forests. The studied forest did not fully recover its initial functional composition even at the lowest forest exploitation intensity, confirming here previous in silico results based on forest simulators (Hiltner et al., 2018). A rotation cycle of 30 years requires thus very 
likely less than 10 trees logged per hectares or a decrease in the volume of trees logged during the following harvesting in order to recover the pre-logging functional composition. We may recall that the exploitation applied in Paracou was strongly damaging (Blanc et al., 2009 and see methods). Thus, while in our study no exploitation intensity permitted the recovery of the initial compositions, we may expect that reduced impact logging (RIL) should decrease the spatial extent of the openings (e.g. Pereira et al., 2002) and fragmentation of the forest (Liu et al., 2018) mitigating the species composition change with the same rotation cycle and logging intensity but formal test are required (Shearman et al., 2012, Griscom et al., 2014). With the same goal i.e. reducing the openings, we may not only choose a minimum diameter of exploitability, but also a maximum diameter or a maximum crown size in order to insure the maintenance of enough shade for late successional species as already suggested by others, but also to ensure the supply of food for potential dispersers. To conclude, we showed that forest exploitation, like hunting (Bello et al., 2015), negatively affected large seeded zoochorous species, and potentially increase the threat on these zoochorous species and their animal vectors.

\section{Conclusion}

Our study emphasizes the need to evaluate forest exploitation in a more integrative way than based on species richness only (Slik et al., 2008, Magnago et al., 2014). We further showed that we may question the sustainability of the common rotation cycle and logging methods used in the tropics and in the humid neotropical forest studied. If conservation of tropical forest functioning and associated ecosystem services remains a priority, our results suggest that governments should favor or impose less damaging logging practices like RIL or longer rotation cycle. Moreover, establishing the cost of this compositional change may be useful for the decision-makers (Chaudhary et al., 2016) and for the logging industry, especially if tree species are replaced by less profitable ones.

\section{Contributions}

PMF, $\mathrm{CF}$ and $\mathrm{BY}$ designed the project. $\mathrm{BY}$ and $\mathrm{CF}$ designed the analyses. All authors discussed the methods and results. BH, SGF, CP, $\mathrm{AM}$ and $\mathrm{AD}$ managed the Paracou plant community database and PMF the seed trait database. SGF, AM and AD participated to the inventory, identification and data depository of the Paracou database. BY performed all the analyses, except the above ground biomass measurements performed by CP. BY, CF and PMF wrote the first draft of the manuscript. All authors improved the manuscript.

\section{Acknowledgments}

We thank the two anonymous reviewers for their many insightful comments and suggestions that helped to improve our manuscript. This study would have not been possible without the long-term dedication of the CIRAD team, especially that of late Laurent Schmitt, Max Dada and Pascal Petronelli, as well as several generations of forets tree spotters and workers who implemented the Paracou experimental plots in the early 1980s, and repeatedly inventoried and re-censused trees in 19842013. BY benefited from a postdoctoral fund from the French national research agency LabEx ANR-10-LABX-0003-BCDiv, in the context of the "Investissements d'avenir" ${ }^{\circ}$ ANR-11-IDEX-0004-02.

\section{Appendix A. Supplementary material}

All data presented in the main text were deposited on figshare with the doi:10.6084/m9.figshare.7376417. Supplementary data to this article can be found online at https://doi.org/10.1016/j.foreco.2018.11. 022 .

\section{References}

Asner, G.P., Rudel, T.K., Aide, T.M., Defries, R., Emerson, R., 2009. A contemporary assessment of change in humid tropical forests. Conserv. Biol. 23, 1386-1395.

Bello, C., Galetti, M., Pizo, M.A., Magnago, L.F.S., Rocha, M.F., Lima, R.A.F., Peres, C.A., Ovaskainen, O., Jordano, P., 2015. Defaunation affects carbon storage in tropical forests. Sci. Adv. 1, e1501105.

Berg, C.C., Rosselli, P.F. (Eds.), 2005. Cecropia. Flora Neotropica. Monograph 94. The New York Botanical Garden, Bronx, New York, pp. 230.

Blanc, L., Echard, M., Herault, B., Bonal, D., Marcon, E., Chave, J., Baraloto, C., 2009. Dynamics of aboveground carbon stocks in a selectively logged tropical forest. Ecol. Appl. 19, 1397-1404.

Bongers, F., Poorter, L., Hawthorne, W.D., Sheil, D., 2009. The intermediate disturbance hypothesis applies to tropical forests, but disturbance contributes little to tree diversity. Ecol. Lett. 12, 798-805.

Cernansky, Rachel, 2017. Biodiversity moves beyond counting species. Nature 546 (7656), 22.

Chaudhary, A., Burivalova, Z., Koh, L.P., Hellweg, S., 2016. Impact of forest management on species richness: global meta-analysis and economic trade-offs. Sci. Rep. 6 .

Chave, J., Coomes, D., Jansen, S., Lewis, S.L., Swenson, N.G., Zanne, A.E., 2009. Towards a worldwide wood economics spectrum. Ecol. Lett. 12, 351-366.

Chave, J., Rejou-Mechain, M., Burquez, A., Chidumayo, E., Colgan, M.S., Delitti, W.B.C., Duque, A., Eid, T., Fearnside, P.M., Goodman, R.C., Henry, M., Martinez-Yrizar, A., Mugasha, W.A., Muller-Landau, H.C., Mencuccini, M., Nelson, B.W., Ngomanda, A., Nogueira, E.M., Ortiz-Malavassi, E., Pelissier, R., Ploton, P., Ryan, C.M., Saldarriaga, J.G., Vieilledent, G., 2014. Improved allometric models to estimate the aboveground biomass of tropical trees. Glob. Change Biol. 20, 3177-3190.

Chisholm, R.A., Muller-Landau, H.C., Abdul Rahman, K., Bebber, D.P., Bin, Y., Bohlman, S.A., Bourg, N.A., Brinks, J., Bunyavejchewin, S., Butt, N., Cao, H., Cao, M., Cárdenas, D., Chang, L., Chiang, J., Chuyong, G., Condit, R., Dattaraja, H.S., Davies, S., Duque, A., Fletcher, C., Gunatilleke, N., Gunatilleke, S., Hao, Z., Harrison, R.D., Howe, R., Hsieh, C., Hubbell, S.P., Itoh, A., Kenfack, D., Kiratiprayoon, S., Larson, A.J., Lian, J., Lin, D., Liu, H., Lutz, J.A., Ma, K., Malhi, Y., McMahon, S., McShea, W., Meegaskumbura, M., Razman, S. Mohd., Morecroft, M.D., Nytch, C.J., Oliveira, A., Parker, G.G., Pulla, S., Punchi-Manage, R., Romero-Saltos, H., Sang, W., Schurman, J., Su, S., Sukumar, R., Sun, I., Suresh, H.S., Tan, S., Thomas, D., Thomas, S., Thompson, J., Valencia, R., Wolf, A., Yap, S., Ye, W., Yuan, Z., Zimmerman, J.K., 2013. Scale-dependent relationships between tree species richness and ecosystem function in forests. J. Ecol. 101, 1214-1224. https://doi.org/10.1111/1365-2745. 12132.

Dalling, J.W., Hubbell, S.P., 2002. Seed size, growth rate and gap microsite conditions as determinants of recruitment success for pioneer species. J. Ecol. 90, 557-568.

Dargie, G.C., Lewis, S.L., Lawson, I.T., Mitchard, E.T.A., Page, S.E., Bocko, Y.E., Ifo, S.A., 2017. Age, extent and carbon storage of the central Congo Basin peatland complex. Nature $542,86$.

Dickinson III, J.C., Putz, F.E., 1992. The tropical forest: competing demands for preservation, exploitation and conversion. Conf. Latin Am. Geogr. 18, 261-275.

Edwards, D.P., Tobias, J.A., Sheil, D., Meijaard, E., Laurance, W.F., 2014. Maintaining ecosystem function and services in logged tropical forests. Trends Ecol. Evol. 29, $511-520$.

Ferreira, J., Lennox, G.D., Gardner, T.A., Thomson, J.R., Berenguer, E., Lees, A.C., Mac, Nally R., Arag ̃̃£o, L.E.O.C., Ferraz, S.F.B., Louzada, J., Moura, N.r.G., Oliveira, V.H.F., Pardini, R., Solar, R.R.C., Vieira, I.C.G., Barlow, J., 2018. Carbon-focused conservation may fail to protect the most biodiverse tropical forests. Nat. Clim. Change 8, 744-749.

Flores, O., Hérault, B., Delcamp, M., Garnier, É., Gourlet-Fleury, S., 2014. Functional traits help predict post-disturbance demography of tropical trees. PLoS One 9 (9), e105022.

Forget, P.M., Sabatier, D., 1998. Dynamics of the seedling shadow of a frugivore-dispersed tree species in French Guiana (vol 13, pg 767, 1997). J. Trop. Ecol. 14, 46.

Gourlet-Fleury, S., Guehl, J.M., Laroussinie, O., 2004. Ecology and Management of a Neotropical Rainforest: Lessons Drawn From Paracou, A Long-Term Experimental Research Site in French Guiana. Elsevier, Paris, pp. 326.

Gourlet-Fleury, S., Mortier, F., Fayolle, A., Baya, F., Ouédraogo, D., Bénédet, F., Picard, N., 2013. Tropical forest recovery from logging: a 24 year silvicultural experiment from Central Africa. Philos. Trans. Roy. Soc. B: Biol. Sci. 368.

Griscom, B., Ellis, P., Putz, F.E., 2014. Carbon emissions performance of commercial logging in East Kalimantan, Indonesia. Glob. Change Biol. 20, 923-937.

Guitet, S.P., Sabatier, D., Brunaux, O., Hérault, B., Aubry-Kientz, M., Molino, J.-F., Baraloto, C., 2014. Estimating tropical tree diversity indices from forestry surveys: a method to integrate taxonomic uncertainty. For. Ecol. Manage. 328, 270-281.

Guitet, S., Sabatier, D., Brunaux, O., Couteron, P., Denis, T., Freycon, V., Gonzalez, S., Hérault, B., Jaouen, G., Molino, J.-F.O., Pélissier, R., Richard-Hansen, C., Vincent, G., 2018. Disturbance regimes drive the diversity of regional floristic pools across Guianan rainforest landscapes. Sci. Rep. 8, 3872.

Hammond, D.S., Gourlet-Fleury, S., van der Hout, P., Ter Steege, H., Brown, V.K., 1996. A compilation of known Guianan timber trees and the significance of their dispersal mode, seed size and taxonomic affinity to tropical rain forest management. For. Ecol. Manage. 83, 99-116.

Herault, B., Ouallet, J., Blanc, L., Wagner, F., Baraloto, C., 2010. Growth responses of neotropical trees to logging gaps. J. Appl. Ecol. 47, 821-831.

Hérault, B., Piponiot, C., 2018. Key drivers of ecosystem recovery after disturbance in a neotropical forest. For. Ecosyst. 5, 2 .

Hiltner, U., Huth, A., Brauning, A., Hérault, B., Fischer, R., 2018. Simulation of succession in a neotropical forest: high selective logging intensities prolong the recovery times of 
ecosystem functions. For. Ecol. Manage. 430, 517-525.

Hogan, J.A., Hérault, B., Bachelot, B., Gorel, A., Jounieaux, M., Baraloto, C., 2018. Understanding the recruitment response of juvenile Neotropical trees to logging intensity using functional traits. Ecol. Appl.

Keenan, R.J., Reams, G.A., Achard, F.d.r., de Freitas, J.V., Grainger, A., Lindquist, E. 2015. Dynamics of global forest area: results from the FAO Global Forest Resources Assessment 2015. For. Ecol. Manage. 352, 9-20.

Laliberté, E., Legendre, P., Shipley, B., 2014. FD: measuring functional diversity from multiple traits, and other tools for functional ecology. R package version 1.0-12.

Leibold, M.A. Chase, J.M., Ernest, S.K.M., 2017. Community assembly and the functioning of ecosystems: how metacommunity processes alter ecosystems attributes. Ecology 98, 909-919.

Liu, J., Coomes, D.A., Hu, G., Liu, J., Yu, J., Luo, Y., Yu, M., 2018. Larger fragments have more late-successional species of woody plants than smaller fragments after 50 years of secondary succession. J. Ecol. https://doi.org/10.1111/1365-2745.13071. (in press).

Magnago, L.F., Edwards, D.P., Edwards, F.A., Magrach, A., Martins, S.V., Laurance, W.F., Bellingham, P., 2014. Functional attributes change but functional richness is unchanged after fragmentation of Brazilian Atlantic forests. J. Ecol. 102, 475-485. https://doi.org/10.1111/1365-2745.12206.

Marcon, E., Hérault, B., 2015. entropart: Entropy Partitioning to Measure Diversity. R package version 1.4.1, http://CRAN.R-project.org/package=entropart. J. Stat. Softw. 67 (8), 1-26.

Martin, Philip A., Newton, Adrian C., Bullock, James M., 2013. Carbon pools recover more quickly than plant biodiversity in tropical secondary forests. “. Proc. R. Soc. B 280 (1773), 22-36.

Martin, P.A., Newton, A.C., Pfeifer, M., Khoo, M., Bullock, J.M., 2015. Impacts of tropical selective logging on carbon storage and tree species richness: a meta-analysis. For Ecol. Manage. 356, 224-233.

Millar, R.B., Anderson, M.J., 2004. Remedies for pseudoreplication. Fish. Res. 70, $397-407$.

Molino, J.F., Sabatier, D., 2001. Tree diversity in tropical rain forests: a validation of the intermediate disturbance hypothesis. Science 294, 1702-1704.

Morales-Hidalgo, D., Oswalt, S.N., Somanathan, E., 2015. Status and trends in global primary forest, protected areas, and areas designated for conservation of biodiversity from the Global Forest Resources Assessment 2015. For. Ecol. Manage. 352, 68-77.

Muscarella, R., Lohbeck, M., Martínez-Ramos, M., Poorter, L., Rodríguez-Velázquez, J.E., Breugel, M., Bongers, F., 2017. Demographic drivers of functional composition dynamics. Ecology 98, 2743-2750. https://doi.org/10.1002/ecy.1990.

Pan, Y., Birdsey, R.A., Fang, J., Houghton, R., Kauppi, P.E., Kurz, W.A., Phillips, O.L., Shvidenko, A., Lewis, S.L., 2011. A large and persistent carbon sink in the world's forests. Science 333 (6045), 988-993 doi:1201609.

Pereira Jr., Rodrigo, Zweedea, Johan, Asnerb, Gregory P., Keller, Michael, 2002. Forest canopy damage and recovery in reduced-impact and conventional selective logging in eastern Para. Brazil. For. Ecol. Manage. 168, 77-89.

Peres, C.A., Emilio, T., Schietti, J., Desmouliere, S.J.M., Levi, T., 2016. Dispersal limitation induces long-term biomass collapse in overhunted Amazonian forests. Proc. Natl. Acad. Sci. USA 113, 892-897.

Pinard, M.A., Cropper, W.P., 2000. Simulated effects of logging on carbon storage in dipterocarp forest. J. Appl. Ecol. 37, 267-283.

Piponiot, C., Sist, P., Mazzei, L., Pena-Claros, M., Putz, F.E., Rutishauser, E., Shenkin, A., Ascarrunz, N., de Azevedo, C.P., Baraloto, C., França, M., Guedes, M., Honorio Coronado, E.N., d'Oliveira, M.V.N., Ruschel, A.R., da Silva, K.t.E., Doff Sotta, E., de Souza, C.R., Vidal, E., West, T.A.P., Herault, B., 2016. Carbon recovery dynamics following disturbance by selective logging in Amazonian forests. eLife 5, e21394.

Putz, F.E. Zuidema, P.A., Synnott, T., Pena-Claros, M., Pinard, M.A., Sheil, D., Vanclay, J.K., Sist, P., Gourlet-Fleury, S., Griscom, B., Palmer, J., Zagt, R., 2012. Sustaining conservation values in selectively logged tropical forests: the attained and the attainable. Conserv. Lett. 5, 296-303.

R Core Team (2015). R: A language and environment for statistical computing. R Foundation for Statistical Computing, Vienna, Austria. < https://www.R-project. org $/>$.

Rejou-Mechain, Maxime, Ariane, Tanguy, Camille, Piponiot, Jerome, Chave, Bruno, Herault, 2017. BIOMASS: Estimating Aboveground Biomass and Its Uncertainty in Tropical Forests. R Package Version 1, 1. https:/CRAN.R-project.org/package= BIOMASS.

Root, R.B., 1973. Organization of a plant-arthropod association in simple and diverse habitats: the fauna of collards (Brassica oleracea). Ecol. Monogr. 43, 95-124.

Rutishauser, E., Wagner, F., Hérault, B., Nicolini, E.-A., Blanc, L., 2010. Contrasting above-ground biomass balance in a Neotropical rain forest. J. Veg. Sci. 21, 672-682.

Rutishauser, E., Hérault, B., Baraloto, C., Blanc, L., Descroix, L., Sotta, E.D., Ferreira, J. Kanashiro, M., Mazzei, L., d'Oliveira, M.V.N., de Oliveira, L.C., Pena-Claros, M., Putz, F.E., Ruschel, A.R., Rodney, K., Roopsind, A., Shenkin, A., da Silva, K.E., de Souza, C.R., Toledo, M., Vidal, E., West, T.A.P., Wortel, V., Sist, P., 2015. Rapid tree carbon stock recovery in managed Amazonian forests. Curr. Biol. 25, R787-R788.

Rutishauser, E., Hérault, B., Petronelli, P., Sist, P., 2016. Tree height reduction after selective logging in a tropical forest. Biotropica 48, 285-289.

Schemske, D.W., Mittelbach, G.G., 2017. "Latitudinal gradients in species diversity": reflections on Pianka's 1966 article and a look forward. Am. Nat. 189, 599-603. Schnitzer, S.A., Carson, W.P., 2001. Treefall gaps and the maintenance of species diversity in a tropical forest. Ecology 82, 913-919.

Shearman, P., Bryan, J., Laurance, W.F., 2012. Are we approaching 'peak timber' in the tropics? Biol. Conserv. 151, 17-21.

Slik, J.W., Bernard, C.S., Breman, F.C., Van Beek, M., Salim, A., Sheil, D., 2008. Woo density as a conservation tool: quantification of disturbance and identification of conservation-priority areas in tropical forests. Conserv. Biol. 22, 1299-1308. https:// doi.org/10.1111/j.1523-1739.2008.00986.x.

Wagner, F., Hérault, B., Stahl, C., Bonal, D., Rossi, V., 2011. Modeling water availability for trees in tropical forests. Agric. For. Meteorol. 151, 1202-1213.

Zanne, A.E., Lopez-Gonzalez, G., Coomes, D.A., Ilic, J., Jansen, S., Lewis, S.L., Miller, R.B., Swenson, N.G., Wiemann, M.C., Chave, J., 2009. Global wood density database. Dryad. Identifier. 